\title{
Insights into Innovation: A Conversation with John Cahn
}

John W. Cahn, emeritus senior fellow, U.S. National Institute of Standards and Technology (NIST), affiliate professor, University of Washington, and a 1983 TMS Fellow, was named the 2011 Kyoto Prize Laureate in Advanced Technology for establishing the theory of three-dimensional spinodal decomposition. His landmark contribution to materials science has facilitated the development of new metals, glass, semiconductors, and polymers with unprecedented characteristics. By taking trial and error out of the development process, Cahn's theory has enabled scientists worldwide to solve the toughest engineering challenges, using "designer" materials with extreme properties of strength, thermal conductivity, pore permeability, heat resistance, and magnetism.

JOM recently had the opportunity to talk with Cahn on several themes that he explored during his 2011 Kyoto Prize Commemorative Lecture. To view his full lecture, go to www.youtube .com/watch?v=B6h9YXIC5sM.

JOM: You used the concept of "serendipity"-how events that you hadn't planned for actually ended up being beneficial-to frame many of your comments during your Kyoto lecture. In listening to your experiences, some would view these "serendipities" as "setbacks." What factors contributed to your achieving positive outcomes from these situations?

Cahn: When everything goes smoothly, there is no challenge. Setbacks wake you up. When something does not go the way you expect, or according to what you've been taught, this is an op-

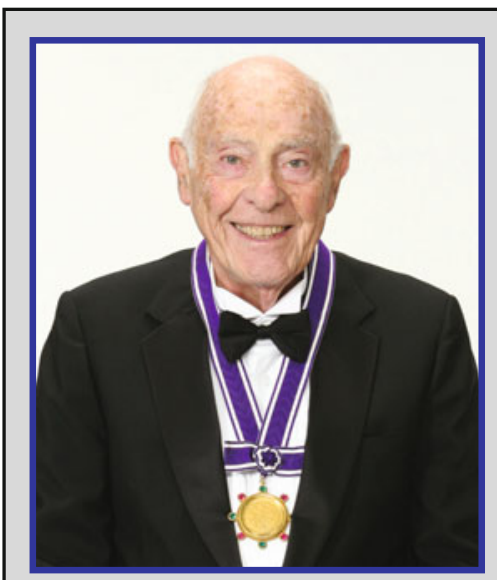

Cahn with his Kyoto Prize medal. A TMS member since 1960, Cahn is also a 1983 TMS Fellow.

portunity to ask, 'What is wrong with the way I've been thinking?' These are very important moments, when things fail or something does not do what it is supposed to do. They remind us that we are in a field where we still don't know all the rules.

This was case with the discovery of quasicrystals. These materials were theoretically illegal-we were told that they could not exist. But, it's situations like this that really awaken my interest. These types of opportunities to exploit new knowledge have made up a really big part of my career.

JOM: You also discuss "paradigm building" in your lecture. In your own experiences, what have been the greatest challenges in trying to introduce new paradigms and alternative ways of looking at problems?

Cahn: Spinodal decomposition was the most difficult one. It was considered an ill-posed problem that had no solu- tion, requiring seven years of work and mathematics that the community did not have. No one understood what I was doing. And, while it was interesting wandering in an unknown field, it was also the hardest thing I've ever done.

Now, much to my surprise, the (Cahn-Hilliard) equation that I developed has become somewhat of a toy for mathematicians. There are at least $50 \mathrm{Ph}$.D. theses by mathematicians that use this equation in ways completely beyond my recognition. The equation solves a lot of problems which occur when things move together, whether it involves populations or economics.

JOM: What do you think you bring to solving these problems that complements or augments the mathematics perspective?

Cahn: Much of my work begins with formulating a problem. If the math exists, I can learn it or get a mathematician to help with the solution. Then, I use the solution to solve a materials problem. Sometimes, the math does not exist, and then it may become a field of research in mathematics. That was true of the Cahn-Hilliard and AllenCahn equations. When mathematicians tell me there is no solution or that the problem is ill-posed, I have work to do. When mathematicians give me solutions that don't fit what I see, I know that the formulation is wrong. Those cases are valuable, because many incorrect formulations have a history of further assumptions to get the wanted answers.

My father always said to me that I could ask questions that would keep ten wise men busy. I guess I've done that all my life. 


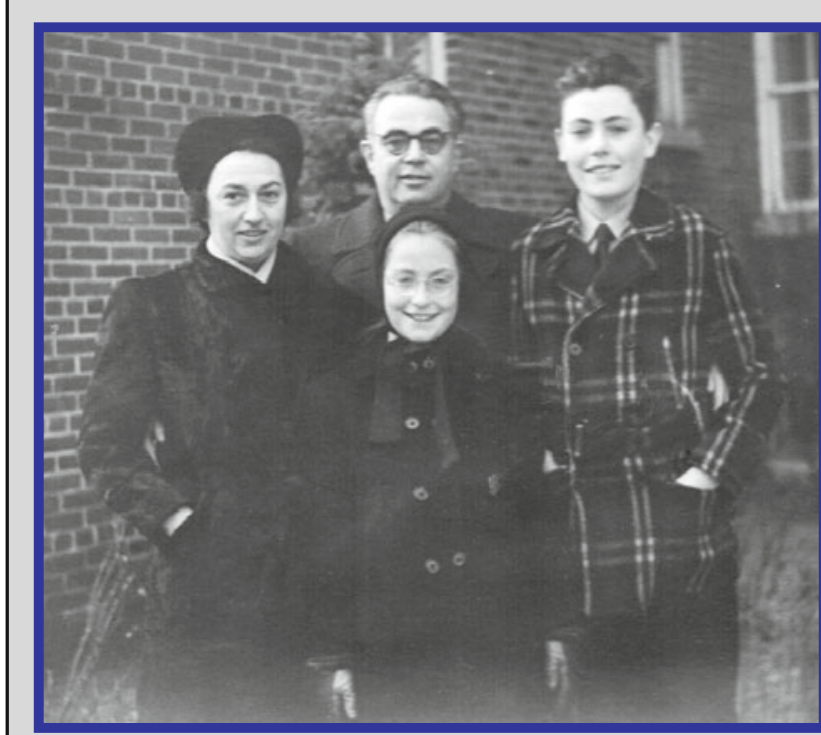

Cahn (right) as a teenager with his father, Felix, his mother, Lucie (nee Schwarz), and sister, Anne. As a small boy, Cahn and his family fled Germany when his father, an attorney, was targeted for arrest by the SS in the early 1930 s for, among other things, assuming several civil cases against Nazis before the party came to power. The Cahns lived in Belgium, Holland, and Italy before emigrating to the United States and finally settling in New York. Cahn attended the Brooklyn Technical High School, where, he noted in his Kyoto Lecture, "I found out how interesting science could be."

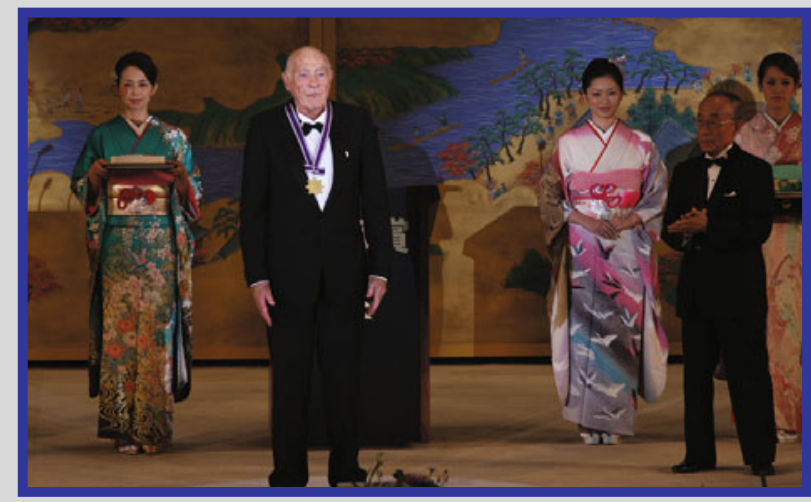

Cahn was formally presented with the Kyoto Prize in Advanced Technology during ceremonies in November 2011. The Kyoto Prize is Japan's highest private award recognizing lifelong contributions to society. He was also honored at the Annual Kyoto Prize Symposium, March 21-22, 2012, in San Diego.

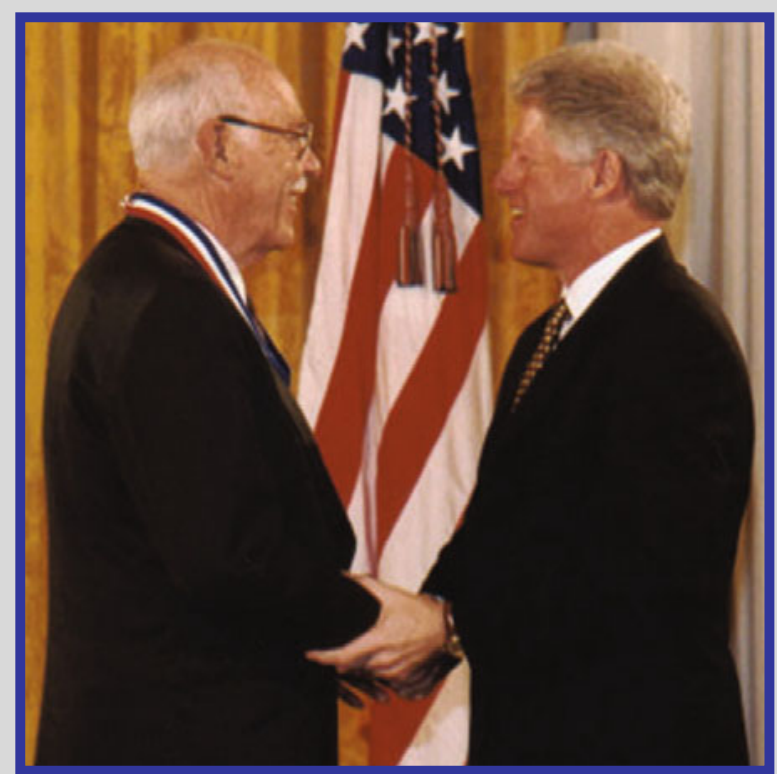

Cahn counts the U.S. Medal of Science, which he received from President Bill Clinton in 1998, among his many honors and awards.

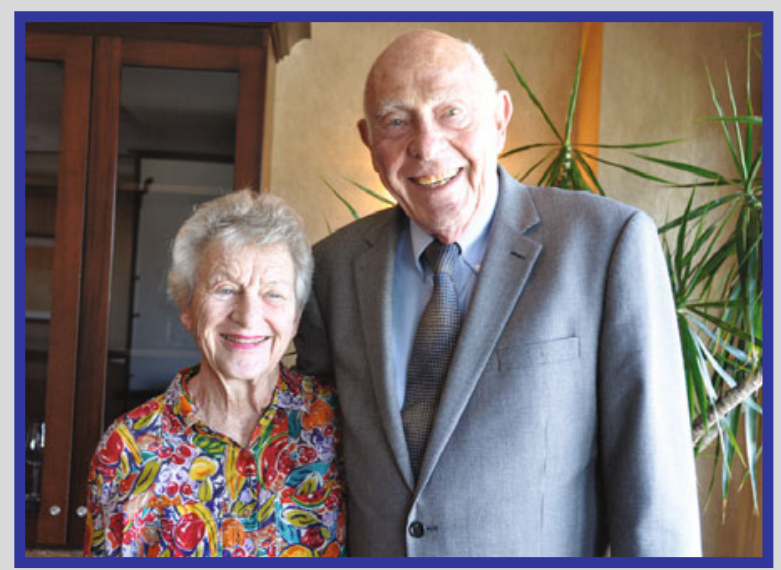

Cahn with his wife, Anne Hessing Cahn, a poltical author and currently Scholar in Residence at American University. Cahn's three children share their father's love for science, although pursuing it in different ways. Martin is a family practice physician in Seattle, Andy is a high school science teacher, and Lori is a groundwater geologist with the Idaho National Engineering and Environmental Laboratory. The Cahns have six grandchildren.

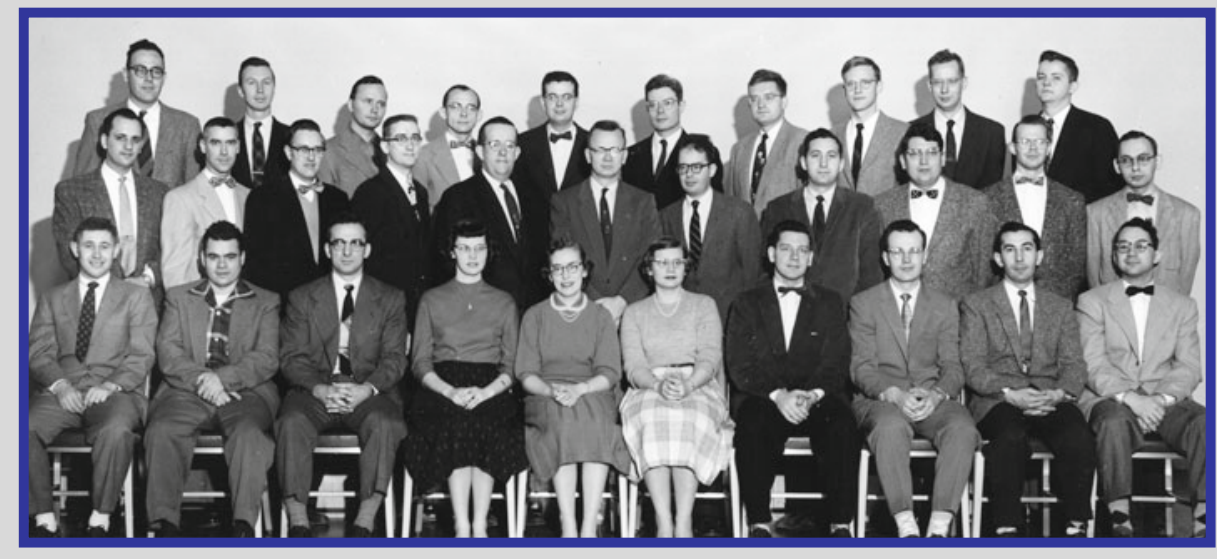

Cahn (third row, last person on the left) with colleagues in the Chemical Metallurgy Division of GE Research Laboratory in 1957. Recalled Cahn about his days at GE, "There was an atmosphere of interaction, in which the managers were good scientists. At times, I would be struggling with a problem, without results, but I would be told that it was a good problem, worth studying and spending time on." He commented that today's culture for managing science, in many instances, is "very different" from the GE model. 
JOM: What have been the most significant turning points in your career and why?

Cahn: First, I was not reappointed as an instructor at the University of Chicago. I had failed, but it ended up being the best thing that could have happened to me, because I was then able to work for the GE Research Laboratory. That's where I learned to do research.

Then, in 1976, while I was working at MIT, my wife (Anne Hessing Cahn) had the opportunity to work in the Carter Administration, which would have meant commuting from Washington, D.C. on the weekends. Instead of her doing that, I got a job with the National Bureau of Standards (now NIST), where I was able to do my own research again and realized that this was what I really liked to do.

JOM: From your days at the GE Research Laboratory and elsewhere, what do you think other organizations could learn in terms of creating an environment for innovation?

Cahn: At GE, there was tremendous internal communication. Everyone knew what everyone else was working on. And, people helped each other and

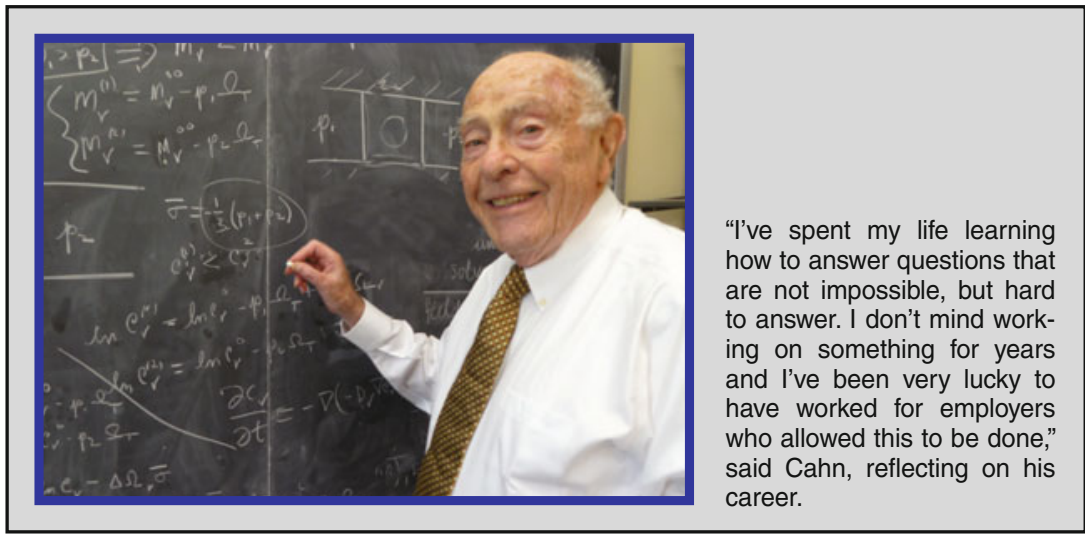

shared information, no matter what their laboratory or project. Our work was supported by assessment from various components of the corporation, so funding was secure. People were very excited about what they were doing and they were free to work on difficult, long-range problems.

JOM: What do you feel are some of the most exciting and promising developments ahead for metallurgy/ materials science?

Cahn: I am not a prognosticator. Too many crowd into the 'most exciting and promising developments,' leading to much duplication of effort, while other developments are ignored. I prefer to wait for opportunities that come from surprising sources, but only for prepared minds.

JOM: Is there any particular advice you would give to scientists just starting their careers?

Cahn: Learn how to learn on your own. Fields move so fast that if you are used to just being taught, you are going to be obsolete in a very short time. Especially if you are in the very forefront, there is probably no professor who can teach you more than you can do on your own. You have to learn without being taught. That's probably the most important thing.

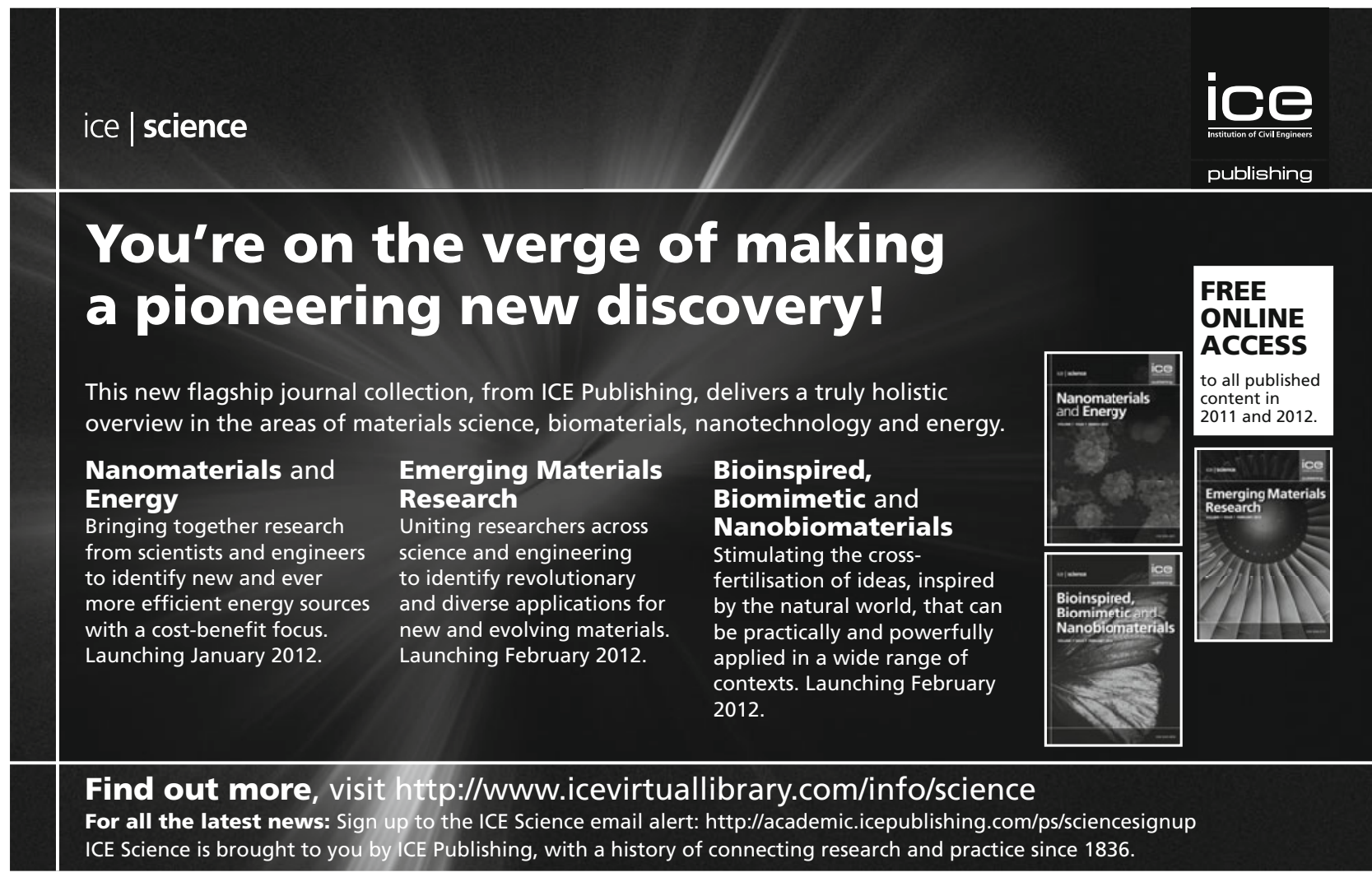

